\title{
The Role of World Bank in the Development of Education in Pakistan
}

\author{
Qazi Arif*; Prof. Dr. Syed Abdul Aziz**; Saima Zareen Ahmed \\ * Research Scholar, Hamdard Institute of Education and Social Sciences (HIESS), Hamdard University \\ Karachi, Pakistan
}

\begin{abstract}
The selection of the research topic was made in the light of reports showing concern about the unsatisfactory state of education in Pakistan and the contribution of international donor agencies particularly the World Bank. The scope of the study was kept limited to primary education, in few districts and few schools of the province of Sindh, Pakistan. The study focused on two segments, part one was comprised of the teachers, students and parents while part two consisted of the physical facilities of the school buildings, furniture, classrooms, its locations and academics. Stratified sampling was used. Methodology adopted for this study was survey. Questionnaire was used to collect the desired data. t-test and chi square statistical tools were used for data analysis. Fifteen (15) hypotheses were formulated for the study. Findings show a high degree of satisfaction of teachers, students and parents. However, a big variation of knowledge, skills and experience was observed among the teachers of different schools. Overall response of the stakeholders, students, teachers, parents, partners and community members were satisfactory with regard to the school performance. Recommendations were made for the improvement in the areas of teachers' training, infrastructure and selection of books.
\end{abstract}

Key Words: Inequality, Accessibility, Quality of Education, Sindh, the World Bank

\section{Introduction}

Importance of learning and education has been acknowledged since the early era of Greeks. The Greeks, particularly are famous for their love of learning and education. Alexander the Great, for instance, built many libraries in most of the countries he subjugated. Well known Greek philosophers like Plato and Socrates considered and realized that knowledge of the art of writing and reading payback more than knowing and learning the art of war. Quite earlier, proper education was recognized; different structures of informal education were already being practiced to feed man's ravenous wish for more awareness (Harris, C 2011).

Governments in different countries realize the worth of education; hence, they allocate a big amount of their budget to enhance and upgrade education and to ensure that all children can have the opportunity to go to school. 2010 The Education Centers Network all rights reserved. Search online education, online degrees, online schools and more at EducationCenters.com)

However, Pakistan, unfortunately, has been put in low Human Development Category (HDC) due to high population growth, weak economy and most importantly low enrollment. According to a comparative study of the factors that verify the Human Development Index of a nation, Pakistan is one of the countries that hardly spend on education. It is a bitter reality that having many five years and tenth years' plans and policies mentioning about the provision of primary education to the children of the country; Pakistan is still struggling with drop outs and low enrollment.

The Province of Sind has got the second largest population of about 42 million and the status of education is disappointing and discouraging.

However, efforts have been made by different NGOs, private institutions and entrepreneurs via donor agencies in order to minimize the gap and spread education in the country.

Sindh Education Foundation (SEF) is one of those who have been playing a significant role working towards the school improvement, better education for children, teachers' capacity building and curriculum development. SEF established in 1991 through Government of Sindh Ordinance has earned great respect and reputation for its performance in the field of education. There are many initiatives for education and development by SEF particularly in rural Sind; in this regard many projects have been run by SEF via USAID and World Bank in order to achieve the targets and Public Private Partnership is one of them.

The study spots light on the part of World Bank for the progress and improvement in education with special reference to PPRS programs in selected schools of targeted districts of Sindh. 


\section{Literature Review}

Education provides the way to bring about the preferred change in society, to develop a generation of righteous individuals and thus add to the development of good human beings. The basic function of education is to increase knowledge, indoctrinate the forms of proper demeanor and acquire technical proficiency. Education gives the way to develop oneself holistically (Asyereamea, 2011).

2011, 01). Importance of Education. StudyMode.com. Retrieved 01, 2011, from http://www.studymode.com/essays/Importance-Of-Education-544114.html

It is believed that the students of age group between 6 to 11 years are most suitable and fertile for printing new messages on their minds. The societies who are concern about their future accentuate on accurate type of education at primary level to all children of this age group, so that secondary level education can be made qualitative. As a result of this an overall socio-economic and moral development can be made possible.

In Pakistan, somehow, like other levels, due focus on primary education was not given. Almost all governments have failed to provide access to all the children of $5-9$ years age group for primary education, and those who got the opportunity to enter in the first level of education could not move to secondary and tertiary levels due to their socio-economic limitations. Presently, we have a large number of population of Pakistani society who are only literate to the extent that they can read and write the basic information but practically unable to play any effective role in changing the culture of their communities in rural areas, except that they are now ready to send their children to schools, if, access and incentives are provided.

In Pakistan, Education Sector Reform Action (ESRA) Plan (2001 - 2005) has somehow addressed the issue of 'access' for primary enrolment, and on the recommendation of World Bank (2005), the traditional criterion of opening a primary school in areas where population is 500 or more, has been replaced and now 'need' is also taken into consideration.

Dakar Conference (April 2000) concluded that purpose of primary education is to modify the behavior of child, in more specific terms the growth of cognitive, psychomotor and effective domain. It also recommended that outcomes of primary education should be a reflection of his behavior through intellectual, spiritual, emotional, physical and social actions.

Alexander, R (2013) suggested that we should critically look at the need and importance of primary education and make sure that the objectives hammering the curriculum and are not merely superficial. The main purpose of primary education is to make children 'secondary ready' is to underestimate children's enormous prospective for growth and learning during the primary years. Education is about present past and as well as the future, in this regard schools must deal with the broader situation and needs and interest of children and society in today's multifaceted world.

Robin Alexander, Friday 4 October 2013 12.30 BST Guardian Professional

Most disappointing and disheartening aspect of the history of primary education in Pakistan, is it's frequently identification of the same type of bottlenecks, troubles, concerns or features accountable for the failure of education policy, plans and strategies primed and presented by the professionals of Pakistan. This observation of the researcher is certified by a study conducted; Shahinshah Babar Khan (2010) in which he reported that primary education in Pakistan could not be upgraded and strengthened due to the following reasons:

- Poverty (Parents)

- Lack of awareness (Parents)

- Cultural situation (Parents/ Community)

- Shortage of teachers (Government)

- School Environment (Government)

- Gap between Curriculum and School

In Pakistan, children of rural areas are highly influenced by the above factors and society or government has failed to address these issues and to attract the children of this age group living in rural areas to avail the opportunity of education.

It is probably in this context that during recent past, donor agencies came up with the idea of directly involving stakeholders through autonomous bodies/ NGOs of reputation as 'partners' for future educational plans, for the purpose of efficient use of funding in some transparent manner, and an inbuilt 'Third Party Monitoring System', for measuring the outcome of Foreign Funded Educational Programs and Projects in Pakistan at national and provincial levels. An important program of this strategic plan is 'Public-Private Partnership'. This program has been a success in the targeted districts and working towards the provision of primary education with the collaboration of public and private sector. The program has brought about an effective change in teaching and learning process in primary schools. 


\section{Research Methodology}

The study was an evaluative study of the PPRS program conducted by the Sindh Education Foundation (SEF) in collaboration with the World Bank. Survey method was adopted in order to collect the opinions of students and teachers. In view of the large geographical and administrative areas and large number of primary schools, cross-sectional survey method was adopted.

Random sampling with a Confidence Level (CL) of 95\% was used and PPRS schools from three (03) districts of Sindh, namely Khairpur, Larkana and Nawabshah were selected and Questionnaire was used as an instrument in order to collect the required data.

Inferential statistical techniques were used for data analysis. Quantitative data for the two groups of respondents; teachers and students were subjected to $\mathrm{Chi}^{2}$-test for the item-wise analysis of the data, and t-test for the testing of hypotheses. For qualitative data, descriptive technique was used.

\section{Findings}

Findings reveal that students, teachers and parents are highly satisfied with the teaching and learning process take place in the schools. In addition to that rural areas of Sindh had been struggling with 'access to education' and World Bank through SEF made it possible to the rural residents to both, male and female children of the poor parents. However, a big deviation of knowledge, expertise, and understanding among the teachers of the sample schools were observed. Also a noticeable difference was seen in the physical infra structure of those schools.

Teachers and students found the physical infrastructure and facilities very helpful and conducive for teaching and learning process.

According to the teachers the support provided by the Sindh Education Foundation regarding professional development has been very facilitating for them. They use Oxford textbooks in order to meet the demand of the given curriculum. However, a few teachers feel that the books published by Oxford should be replaced by the Sindh Textbooks since they are more contextual and relevant.

School teachers in general are satisfied except a few with regard to separate office/ room of principal/ administrator.

The researcher found difference of the opinion of school a, b, \& c teachers with regard to teacherstudent ratio which indicates that the school administrations don't have any declared policy in this regard. The administration of school ' $\mathrm{d}$ ' seems to be following their school policy because all teachers shared that their teacher students ratio is $1: 20$.

Students were found happy and satisfied with the teachers' styles of teaching and use of different teaching aids and activities. They also appreciated the friendly behavior of their teachers.

Overall response of the stakeholders, students, teachers, parents, partners and community members were satisfactory with regard to the school performance.

\section{Conclusion}

Change does not occur rapidly it takes time and extra efforts have to be put in order to see the effective improvement. The data revealed that World Bank is playing a vital role in the development of Education in Pakistan especially in the province of Sindh. In this connection SEF is utilizing the funds of World Bank in a meaningful way by implementing the PPRS program effectively. They have blended the role of public and private sector in a very unique manner. Hence through PPPRS program the curriculum, teachers' training, \& physical infra structure and co-curricular activities have been modified and improved.

\section{Recommendations}

In the light of findings and conclusion, following recommendations have been made:

- To address the poverty-education issues, NGOs and public partnerships must be established through fostering greater confidence of government on NGOs working in the education sector

- In addition to providing instructional materials, it is recommended to invest more in school structures including classrooms, libraries, gender sensitive facilities, and providing a safe water supply to all schools

- Oxford Textbooks should be replaced with Sind Text Books

- Duration of teachers training sessions should be extended

- More content-based training sessions for the teachers should be included

- More follow-up and monitoring activities are recommended in order to upgrade the present status of curriculum, teachers' teaching practices, role of entrepreneurs and students' enrollment 


\section{References}

[1] Education in Pakistan_http://www.worldbank.org.pk ... the site pk: 293052,00.html)

[2] Good, Thomas L. \& Brophy, Jere E. (1988). Looking into Classrooms (4 $4^{\text {th }}$ Edition). New York: Harper and Row

[3] Harris, C. (2011). Importance of Education. StudyMode.com. Retrieved 01, 2011, from http://www.studymode.com/essays/Importance-Of-Education544114.html

http://www.iep.utm.edu/spencer/

http://www.renaissance.com.pk/aprefl20.htm

http://www.sdpi.org/publications/files/W-119.pdf

http://www.vision.org/visionmedia/article.aspx?id=598

http://www.worldbank.org.pk/contentMDK:21608863/thesitepk.293052,00.html

Lieten, K. (2004). Views on Development. The Local and the Global in India and Pakistan, New Delhi: Three Essays Collective

NCHD 2010, National Commission for Human Development, Islamabad, Pakistan, <http://www.nchd.org.pk> Accessed 22 March 2013

Neagley, R.I. and Evans, N.D., Hand book of Effective Curriculum, 1967

SPARC. 2004, 'The State of Pakistan's Children 2003'. Islamabad: Society for the Protection of the Rights of the Child, Islamabad, Pakistan

The Education Centers Network all rights reserved. Search online education, online degrees, online schools and more at EducationCenters.com)

[14] Towards universalizing Primary Education in Pak. Modern book, Islamabad, (1987) pp. 1-11 \& 32-39

[16] UNICEF. (2007). The State of the World's Children 2008: Child Survival. New York 